\title{
RELAÇÕES COM MÚSICA NA EDUCAÇÃO INFANTIL: CENAS DE UMA ESCOLA MUNICIPAL DE EDUCAÇÃO INFANTIL EM PORTO AlEgRE/RS
}

\author{
Relations with music in early childhood \\ education: scenes from a municipal school of \\ early childhood education in Porto Alegre/RS
}

\author{
Relaciones con música en la educación \\ infantil: escenas de una escuela municipal de \\ educación infantil en Porto Alegre/RS
}

\author{
JoAna Lopes Pereira \\ Universidade Federal do Rio Grande do Sul \\ joana.joanalp@gmail.com
}

\begin{abstract}
Resumo: Este artigo apresenta um recorte de uma pesquisa que teve como objetivo compreender como diferentes formas de mediar relações com música, de diferentes profissionais, contribuem para o projeto formativo de crianças em uma escola de educação infantil. Os pressupostos orientadores tomam como base ideias de infância, de educação e de música. A estratégia de pesquisa escolhida foi o estudo de caso e as técnicas, a análise de documentos, a entrevista semiestruturada e a roda de conversa. Os resultados evidenciam que o projeto formativo particulariza a escola e direciona os campos de conhecimento para um objetivo comum: a educação das crianças que introduziram seus inícios nessa instituição. A música - como um desses campos de conhecimento - funciona como dispositivo de formação das crianças.
\end{abstract}

Palavras-chave: Música na educação infantil. Projeto formativo de crianças. Modos de mediar as relações com música.

\begin{abstract}
This paper presents results of a research that aimed to understand how different ways of mediating relationships with music, of different professionals, contribute to the formative project of children in a kindergarten school. Guiding assumptions are based on ideas of childhood, education and music. The research strategy was the case study, and the techniques were document analysis, semi-structured interview and conversation wheel. The results show that the formative project individualizes the school, and directs the fields of knowledge to a common goal: the education of children who introduced their beginnings in this institution. Music - as one of these fields of knowledge - acts as a device for the education of children.
\end{abstract}

Keywords: Music in early childhood school. Formative project. Modes of mediating relationships with music.

Resumen: Este artículo presenta un fragmento de una investigación que tuvo como objetivo comprender cómo diferentes formas de mediación de las relaciones con música, por parte de diferentes profesionales, contribuyen al proyecto de formación de los niños en una escuela de educación infantil. Los supuestos rectores se basan en ideas de la infancia, la educación y la música. La estrategia de investigación elegida fue el estudio de caso y las técnicas, el análisis de documentos, la entrevista semiestructurada y el círculo de conversación. Los resultados muestran que el proyecto de formación particulariza la escuela y orienta los campos de conocimiento hacia un objetivo común: la educación de los niños que introdujeron sus inicios en esta institución. La música, como uno de estos campos del conocimiento, funciona como un dispositivo de formación para los niños.

Palabras clave: Música en la educación infantil. Proyecto de formación de niños. Formas de mediar las relaciones con música. 


\section{DO PONTO DE PARTIDA AO PROBLEMA DE PESQUISA}

Este artigo apresenta um recorte de pesquisa que teve como tema as relações com música no contexto da educação infantil. ${ }^{1} \mathrm{O}$ interesse pela temática toma como ponto de partida meu vínculo com as escolas de educação infantil, que está relacionado não somente às minhas atividades profissionais, mas, também, acadêmicas, mais especificamente, à pesquisa sobre música e educação infantil que realizei anteriormente (Pereira, 2015). Dessa pesquisa, retomei alguns pontos que considerei relevantes para compreender o modo como as pesquisas em educação musical têm abordado a educação infantil, bem como as práticas musicais desenvolvidas nas escolas.

O primeiro desses pontos foi a revisão de literatura. Essa revisão revelou que a música estava presente em diversas instituições de educação, mas percebi que muitas produções viam de maneira crítica o modo como o trabalho com música era desenvolvido nos contextos investigados, o que pode ser percebido, por exemplo, quando se entende que há "uma prática 'utilitarista da música"' (Scarambone, 2014), que a música é "tratada apenas como entretenimento" (Duarte; Kebach, 2010, p. 185) ou que "as atividades musicais são desenvolvidas de maneira superficial" (Martinez; Pederiva, 2012, p. 218). Essas impressões são trazidas quando as autoras identificam a utilização da música para as rotinas escolares, para as datas comemorativas e para auxiliar o processo de alfabetização ou para a aprendizagem de outros conteúdos (Pereira, 2015).

O segundo ponto refere-se a alguns resultados da pesquisa, referentes ao envolvimento dos sujeitos escolares na construção de seu trabalho. Nessa pesquisa anterior, contei com a colaboração de quatro professores e uma professora de música que, assim como eu, atuavam no município de Porto Alegre, em escolas municipais de educação infantil (Emeis). Identifiquei que esses(as) profissionais buscaram construir suas trajetórias de trabalho tomando como referência suas experiências anteriores: formação, atuação em múltiplos contextos e outras experiências com música. Concluí que as trajetórias de trabalho de cada um(a) são singulares e foram construídas na própria escola, através da interação com outros profissionais e com as crianças. Percebi, ainda, que ela e eles estavam envolvidos com algo maior: uma proposta pedagógica para a formação de crianças, que é coletiva.

Revisitando a literatura então revisada, constatei que o foco das pesquisas esteve mais voltado para a presença da música e para atividades musicais desenvolvidas no contexto da educação infantil do que para a interação dos sujeitos escolares com a música. Assim, para desenvolver a nova pesquisa, procurei identificar, na literatura da educação musical, indícios de como a música se integrava a uma proposta pedagógica na etapa da educação infantil.

\footnotetext{
1 Trata-se de minha tese de doutorado, defendida no Programa de Pós-Graduação em Música da Universidade Federal do Rio Grande do Sul, orientada pela professora Luciana Del-Ben.
} 
A partir da análise da produção da área, percebi que grande parte das pesquisas investigou a formação e as práticas educativo-musicais realizadas por professores(as) unidocentes, o que era esperado, já que esses(as) são os(as) profissionais responsáveis pela atuação nessa etapa da educação básica. Entretanto, há pesquisas que demonstram a presença de professores(as) de música no contexto da educação infantil (Pereira, 2015; Röpke, 2017).

Além disso, percebi que, frequentemente, há uma percepção negativa acerca das práticas educativo-musicais desenvolvidas por professores(as) unidocentes no contexto da educação infantil, proveniente do entendimento de que o conhecimento musical é trabalhado de maneira superficial e de que a música é subutilizada, pois serve a finalidades que não as da área, mesmo que nem sempre essas finalidades sejam apresentadas, fundamentadas ou discutidas. Isso pode percebido, por exemplo, quando Spanavello e Bellochio (2005, p. 93), afirmam que "os professores [unidocentes] reconhecem a validade da música no âmbito das suas práticas, mas não desenvolvem-na de forma tão coerente com os objetivos da área, justamente por sentirem-se desprovidos de saberes docentes capazes de lhes dar suporte para tais atividades".

Diante disso, a literatura aponta o trabalho colaborativo como forma de qualificar as práticas educativo-musicais nesse contexto, sendo que essa colaboração é pensada apenas entre professores(as) e na direção de qualificar as práticas educativo-musicais, o que pode ser percebido nas palavras de Figueiredo (2007, p. 34):

a presença do especialista em música poderia contribuir para o aprofundamento de atividades musicais, mas o professor generalista é aquele que está com as crianças a maior parte do tempo e poderia aproveitar muitas situações para incluir música no cotidiano escolar.

O foco dos trabalhos, portanto, está no que particulariza a música na escola, e não no que a une à escola "ou seja: crianças, jovens e adultos, que participam de projetos educativos que, de diferentes maneiras, visam à formação para uma vida em sociedade, uma vida comum, marcada por pluralidades, diferenças e incertezas" (Del-Ben; Pereira; Macedo; Gaulke; Pimentel; Cotrim; Fracasso; Puerari; Daenecke; Pedrini, 2016, p. 563). Dessa maneira, não foi possivel compreender, a partir da literatura, as relações com música como parte de um projeto formativo, entendendo a educação musical como um projeto coletivo, que é concebido e desenvolvido por diferentes profissionais: professores(as), tanto unidocentes quanto especialistas, e, também, outros(as) profissionais que atuam junto às crianças.

A partir dessa problematização, estabeleci como objetivo geral da pesquisa compreender como diferentes formas de mediar relações com música, de diferentes profissionais, contribuem para o projeto formativo de crianças em uma escola de educação infantil. Esse objetivo se desdobrou nos seguintes questionamentos: que ações e práticas envolvendo música são desenvolvidas na escola? Quem as desenvolve? Como são pensadas e desenvolvidas? 
Quais são as percepções das profissionais sobre as contribuições das ações e práticas envolvendo música para a formação das crianças?

\section{PRESSUPOSTOS ORIENTADORES}

Para dar suporte teórico ao trabalho, elenquei um conjunto de proposições sobre três eixos: infância, educação e música, a partir, respectivamente, das proposições de Walter Kohan, Gert Biesta e Wayne Bowman. São proposições que se complementam e, assim, me possibilitaram construir compreensões sobre modos de realizar a educação de crianças por meio da música.

Kohan faz referência à forma como as crianças vivenciam o tempo e apresenta uma forma de compreender a infância. Para ele a "infância é tanto ausência quanto busca de linguagem; só um infante se constitui sujeito da linguagem e é na infância que se dá essa descontinuidade especificamente humana entre o dado e o adquirido, entre a natureza e a cultura" (Kohan, 2004, p. 9). Partindo desse pressuposto, o autor percebe que a "infância não é apenas uma questão cronológica, mas uma condição de experiência" e afirma ser "preciso ampliar os horizontes da temporalidade" (Kohan, 2004, p. 9).

Para Kohan, há diversas temporalidades que constituem e perpassam a infância. Ele toma como base três definições gregas de tempo: chrónos, kairós e aión. Chrónos "designa a continuidade de um tempo sucessivo" (Kohan, 2004, p. 54). Assim, "o tempo é, nessa concepção, a soma do passado, presente e futuro, sendo o presente um limite entre o que já foi e que não é mais (o passado) e o que ainda não foi e, portanto, também não é, mas será (o futuro)" (Kohan, 2004, p. 54). Kairós significa "oportunidade" (Kohan, 2004, p. 54) e sinaliza que há momentos específicos para se realizar determinadas ações. Aión, por sua vez, significa "a intensidade do tempo da vida humana, um destino, uma duração, uma temporalidade não numerável, nem sucessiva, intensiva" (Kohan, 2004, p. 54). A infância no tempo de aión é entendida "[...] como experiência, como acontecimento, como ruptura da história, como revolução, como resistência e como criação" (Kohan, 2004, p. 53). A infância sob essa perspectiva é "uma forma de estar no mundo associada não aos anos que se tem, mas à experiência de vida que se afirma” (Kohan, 2012, p. 43).

Essas noções de temporalidade me auxiliaram a entender que as crianças são seres recém-chegados ao mundo, que se encontram em uma etapa que vai além da cronologia por ser uma condição de experiência.

A educação, para Biesta (2017, p. 16), é "uma intervenção na vida de alguém; uma intervenção motivada pela ideia de que tornará essa vida, de certo modo, melhor, mais completa, mais harmoniosa, mais perfeita - e talvez até mais humana". Desse modo, o autor sinaliza que a educação tem finalidade e intencionalidade, o que fortalece a relevância do trabalho de professores(as), tendo em vista que as relações se tornam educativas a partir da intencionalidade desses(as) profissionais. O autor aponta a necessidade de pessoas que estejam "[...] dispostas a assumir o risco, a arriscar-se a si mesmas para o futuro de modos humanos de existir juntas" (Biesta, 2018, p. 29). 
Esses modos humanos de as pessoas existirem juntas ocorrem em um lugar específico: a escola. Nesse lugar ocorre a educação, que é entendida

[...] como um encontro entre criança e mundo, no qual e através do qual a criança adquire uma certa "forma". Esse encontro não pode ser entendido como a simples impressão da forma do mundo na criança. É um encontro no real sentido da palavra, em que algo acontece na criança e no mundo (Biesta, 2018, p. 22-23).

O encontro da criança com o mundo é mediado pelos(as) profissionais, o que me leva a compreender a escola de educação infantil como um lugar de encontro entre profissionais, crianças e mundo. Com base nas ideias de Kohan, entendo as crianças como seres humanos recém-chegados que, na interação com outros seres humanos e explorando o mundo, vão realizando suas descobertas e inventando novas formas de interagir com esse mundo.

A partir das ideias de Biesta, entendo que a educação pressupõe uma relação entre pessoas que convivem em um mesmo ambiente - a escola, sendo as professoras e professores responsáveis pelas intervenções, considerados o contexto em que a instituição está inserida, o projeto formativo da escola, os documentos legais para cada etapa da educação e as vivências dos alunos e alunas que frequentam a instituição. O autor defende a ideia de "pensar na educação como dizendo respeito antes de tudo às oportunidades de os seres humanos virem ao mundo, encontrarem sua própria voz, virem a se constituir como seres únicos, singulares" (Biesta, 2017, p. 83).

Biesta (2017, p. 80) sustenta que "o que nos 'torna' um ser único, singular, não é nossa identidade, não é um conjunto de atributos que só pertencem a mim, mas é o fato de que eu sou responsável e de que eu não posso escapulir dessa designação". Desse modo, nossa unicidade e singularidade só podem existir pela existência da presença de outros que são diferentes de mim.

Wayne Bowman, em produções mais antigas, apresenta o som e seu significado no mundo antes de tratar da música propriamente. Para o autor, o som é "[...] um modo totalmente único de interpretar e construir o mundo" (Bowman, 1994a, p. 53). ${ }^{2}$ Além disso, compreende que "[o] imediatismo peremptório do som, sua ambiguidade, sua difusão e sua transitoriedade vital concedem à existência humana dimensões experienciais qualitativas incomparáveis com qualquer outro campo, que não se encontra em qualquer outra área" (Bowman, 1994a, p. 53). Sendo assim, entende que "[o]s sons contribuem profundamente para o nosso senso de estar vivo para o mundo. Eles afirmam nosso vínculo com o mundo e confirmam sua unidade" (Bowman, 1994a, p. 53).

A partir de sua percepção sobre o som Bowman (1994a, p. 54) acredita que "[o] som musical transforma esses fenômenos pessoais em sociais

2 Os excertos de Wayne Bowman foram traduzidos do inglês para o português e todas as traduções foram feitas por mim. 
por causa de sua notável capacidade de nos cercar e de criar sincronicidade entre nós". O autor argumenta que "[a] natureza e o valor da música não são absolutos, mas o resultado da intenção e convenção. Músicas não são fatos da natureza, mas produtos contingentes do comportamento humano e interação" (Bowman, 1994a, p. 55), sendo um processo de "construção ativa" (Bowman, 1994a, p. 51).

Para Bowman (1994b, p. 64) "[n]ão existe música fora das esferas humanas, sociais, políticas e, portanto, das interações morais”. Ele entende que músicas são "modos vivos de estar no mundo e de ser presentes um ao outro. Músicas são ações que afirmam e vivificam a existência. Elas não apenas refletem quem somos, mas ajudam a criar e nos definir" (Bowman, 1994b, p. 65).

A partir das premissas trazidas por Bowman (1994a, 1994b) - para quem o som é um modo singular de interpretar e construir o mundo; o som musical transforma experiências pessoais em sociais; essas experiências criam sincronicidade entre as pessoas; música é um processo de construção ativa; músicas são ações que vivificam a existência -, entendo que a música na escola tem a potencialidade de oportunizar experiências singulares aos sujeitos envolvidos no projeto formativo.

\section{Metodologia}

O estudo de caso foi a estratégia de pesquisa adotada, tendo em vista a busca por compreender "a particularidade e [a] complexidade de um caso singular, para chegar a compreender sua atividade em circunstâncias importantes" (Stake, 1999, p. 16, tradução minha). O caso escolhido foi uma escola municipal de educação infantil: a Emei Maria Marques Fernandes, situada na Vila Mapa, no bairro Lomba do Pinheiro, na cidade de Porto Alegre.

Nessa escola, havia profissionais que desenvolviam um trabalho especificamente voltado à música: uma professora vinculada a um projeto social e uma professora de música concursada. A primeira desenvolvia oficinas com as turmas de jardins (crianças entre 4 e 5 anos e 11 meses). Além dessa profissional, trabalhei como professora de música na instituição entre 2012 e 2017, atuando com todas as turmas, que compreendiam a totalidade da faixa etária da educação infantil.

As estratégias para a coleta de dados foram escolhidas de modo a abordar tanto percepções individuais quanto coletivas. A entrevista semiestruturada, com profissionais - professoras e monitoras ${ }^{3}$ - que desempenhavam diferentes funções na escola: vice-diretora, coordenadora pedagógica, professoras unidocentes, professora de educação física e monitoras me possibilitou compreender as individualidades de cada uma das colaboradoras.

As outras duas estratégias foram a análise de documentos e a roda de conversa, que me permitiram construir uma visão do coletivo. A partir da

\footnotetext{
3 Profissionais com curso de educador assistente, que atuam junto às crianças.
} 
análise do projeto político-pedagógico da escola, pude compreender o modo com a comunidade escolar organizou as reflexões sobre as intenções educativas para a formação das crianças na instituição. A roda de conversa, por sua vez, me permitiu aprofundar elementos que foram recorrentes nas entrevistas individuais.

Os dados foram analisados tomando como base princípios da teoria fundamentada (Charmaz, 2009), partindo de uma codificação inicial, próxima aos dados empíricos, passando por uma codificação focalizada (sintetizando as informações da codificação inicial) e chegando a uma codificação teórica. A seguir, apresento parte dos resultados da pesquisa, dando ênfase às cenas cotidianas da escola em que as relações com música estão presentes, bem como seu potencial formativo.

\section{DOS INÍCIOS NO MUNDO AO ENCONTRO}

A escola é tomada como o primeiro "sujeito" que introduz seu "início" (Biesta, 2017) no mundo, lugar sem o qual não seriam possiveis os outros inícios. Essa escola também é entendida como um mundo, pois é o lugar onde todos os sujeitos - profissionais e crianças - "introduzem seus inícios" como "seres únicos e singulares" (Biesta, 2017, p. 181).

A Emei Maria Marques Fernandes é fortemente vinculada à comunidade em que se localiza, a Vila Mapa. A própria construção da instituição ficou a cargo da comunidade. "Foi um trabalho de 'equipe'. Todos os moradores participaram desta construção" (Emei Maria Marques Fernandes, 2018, p. 4). A história da escola tem um tempo cronológico de 50 anos, mas tempos de kairós e aión vivenciados por quem ali trabalha. Assim, as colaboradoras da pesquisa também ajudaram a construir essa história, desde que nela introduziram seus inícios.

Assim como entendi a história da escola como um início da mesma no mundo, compreendo, inspirada em Biesta, o início da trajetória de cada profissional nessa escola como um nascimento, um momento em que as professoras e monitoras "introduzem seus inícios" como "seres únicos e singulares" (Biesta, 2017, p. 181). Foram nove profissionais que colaboraram com a pesquisa, que ocupam diferentes funções na escola.

Quatro delas são monitoras: Luciana, Andreia, Bruna e Samanta. As duas primeiras trabalham na escola há 19 anos, Bruna ingressou no ano de 2014 e Samanta, em 2017. Apenas Luciana não tem habilitação para ser professora; Andreia cursou pedagogia, Samanta fez magistério e, posteriormente, pedagogia e Bruna fez magistério e estava concluindo o curso de pedagogia no momento da entrevista.

Outras cinco colaboradoras são professoras, sendo que Mariana é professora de educação física e as demais são pedagogas. $\mathrm{Na}$ ocasião das entrevistas, Mary e Fábia trabalhavam como professoras, Ana atuava como coordenadora pedagógica e Isabel, como vice-diretora. Todas as professoras têm pelo menos um curso de especialização e duas delas fizeram mestrado. 
Os inícios das colaboradoras são compartilhados com outros inícios: os das crianças. Sobre o vínculo das crianças com a música, as profissionais disseram que "[elas] adoram música" (Mary); e que a aula de música "é um momento bem significativo, eu acho, pra [elas]. [...] [elas] têm bastante envolvimento e gostam muito de música" (Samanta).

Os inícios de cada uma só são possiveis porque outras adotam seus inícios. Assim, sua unicidade e singularidade só existem pela presença dos outros, como ilustra a fala de Ana: "Eu sei que, se eu chegar lá na escola e eu não conseguir dar conta, o [diretor e a vice-diretora da escola vão] me ajudar [...]. Se as gurias não tão conseguindo, eu vou ajudar elas. E eu acho isso muito bonito, enquanto história de grupo [...]." A introdução dos diferentes inícios e a disposição que as colaboradoras têm para os outros sujeitos possibilitam que na escola ocorra um encontro.

O trabalho desenvolvido na Emei Maria Marques Fernandes baseia-se na coletividade, no sentido de ser algo que pertence a várias pessoas e que está acima de cada indivíduo, o que é evidenciado no respeito com que tratam a instituição, o que pode ser percebido na fala de Mary: "O coletivo, na verdade, se completa, porque cada um tem uma coisa que faz melhor. Eu acho que isto é o importante do coletivo: cada um tem alguma coisa que pode doar para o outro."

Entendo que a construção de um trabalho conjunto se dá a partir do encontro entre profissionais, o que relaciono à ideia de Biesta (2017, p. 155), ao afirmar que "[...] o mundo em que nos tornamos presença é um mundo de pluralidade e diferença, pois só podemos vir ao mundo se outros, que não são como nós, adotam nossos inícios de tal maneira que possam também introduzir os seus inícios no mundo".

Identifico esse encontro em função da disposição das colaboradoras para aprender umas com as outras e para valorizar o que as outras fazem, ainda que o fazer do outro seja diferente. Isso faz com que as profissionais se entendam como um coletivo, pois se sentem pertencentes à instituição, são parte dela e a constituem, e possibilitam compreender os outros a partir de sua outridade (Biesta, 2017), o que pode ser percebido quando Mary diz que as diferentes formas de mediar as relações com música "[...] se interconectam e formam a pessoa como um todo. Um pouquinho aprendo com a [professora de música], um pouquinho aprendo com a professora [unidocente] e um pouquinho aprendo a tocar o instrumento em uma outra aula." No entendimento da professora, as crianças vão aprender um pouco de música com cada uma das profissionais, o que indica que todas as formas são relevantes e que seu trabalho com música, apesar de diferente, não é menos importante do que o trabalho desenvolvido por uma professora licenciada ou por uma professora da oficina. ${ }^{4}$

\footnotetext{
4 As oficinas de música ocorriam semanalmente, com turmas de jardins, e eram ministradas por professoras vinculadas a um projeto social que ocorre na comunidade da Vila Mapa. Essas oficinas enfatizavam a prática instrumental com instrumentos de percussão.
} 
$\mathrm{Na}$ escola - mundo em que os sujeitos se encontram - as singularidades das profissionais encontram um objetivo comum: a educação das crianças que ali introduziram seus inícios. A escola nasce com esta função: a educação das crianças, no sentido de tornar a vida dessas crianças melhor, buscando "fazer o máximo pensando na criança" (Samanta) e "fazer o que [podem] de melhor" (Fábia). Desse modo, as mais variadas ações que ocorrem na escola se tornam pedagógicas, pois buscam contribuir para a formação das crianças.

Percebo que os aprendizados que fizeram umas com as outras possibilitaram que as profissionais compreendessem melhor as crianças, refletissem sobre suas ações educativas e repensassem suas práticas, como ilustra a fala de Ana:

[...] muita coisa mudou. A questão das crianças se tornarem mais protagonistas, nos minimos detalhes, desde servir a salada no almoço, pegar o copo de água no corredor, se servir no aniversário, pequenas coisas, sabe? Que a gente mudou o nosso olhar [...] na verdade, são coisas que formam eles num todo, né? São pequenas ações que formam eles num todo. Então, eu acho que a gente avançou muito pedagogicamente, o nosso olhar.

As práticas educativo-musicais também foram aprimoradas por meio do compartilhamento de experiências, como é possível perceber no relato de Luciana:

Eu acho que a gente trabalhava com música, mas a gente não tem aquele traquejo, vamos dizer. Então, tu [...] por ser professora de música, tu já procura muito mais outras coisas, de brincadeiras com música e tal. A gente, não. A gente fazia aquela roda cantada, no meu caso, eu explorava um pouco mais, mas o pessoal fazia uma rodinha cantada e algumas brincadeiras que dava pra fazer com música. Mas agora, depois que tu veio, foi bem melhor [...] a gente conheceu coisas que... a gente aprendeu a fazer coisas que a gente não sabia fazer antes, que já existiam, mas que a gente não sabia.

Os excertos acima sinalizam que o encontro entre as profissionais possibilita que elas aprendam, reflitam e modifiquem sua forma de trabalhar, construindo o trabalho coletivamente. Além disso, possibilita a convivência entre diferentes formas de mediar as relações com música nessa escola de educação infantil, considerando que nesse lugar há diferentes profissionais que medeiam as relações com música: professoras unidocentes, monitoras, professora de educação física, professora de música e professora vinculada a um projeto social que desenvolve uma oficina de música. Na escola, a organização das ações educativas é feita através de projetos, sendo que sempre há um projeto da escola e projetos individuais das turmas, buscando "assegurar os direitos das crianças se desenvolverem e construírem uma compreensão do mundo e de si próprio pautados em valores que visam promover um 
mundo mais justo, respeitoso, colaborativo e igualitário" (Emei Maria Marques Fernandes, 2018, p. 23).

Partindo da perspectiva de Bowman, para quem o som é "[...] um modo totalmente único de interpretar e de construir do mundo" (Bowman, 1994a, p. 53) e que as músicas "[...] não apenas refletem quem somos, mas ajudam a criar e nos definir” (Bowman, 1994b, p. 65), percebo que a intenção de oportunizar que crianças construam uma compreensão do mundo e de si pressupõe o acesso às diferentes formas pelas quais o mundo se constrói, sendo a música uma dessas formas, que também nos cria e nos define.

\section{CENAS COTIDIANAS COM MÚSICA NA EDUCAÇÃO INFANTIL E SEU POTENCIAL FORMATIVO}

Seguindo a ideia de Bowman (2014), para quem "[o] valor da música e [o] do estudo da música e [o] da experiência musical (e assim por diante) não são simplesmente 'dados' ou inerentes [...]. Eles são bons apenas na medida em que contribuem para fins humanos ou, no caso da educação musical, para fins educacionais", analiso as práticas musicais desenvolvidas na Emei Maria Marques Fernandes buscando identificar seu potencial formativo. Essas práticas foram organizadas em cenas, que ilustram as relações com música em diferentes momentos da escola. Para compreender algumas de suas particularidades, recorro, além dos autores que constituem a sustentação teórica deste trabalho, à literatura da área de educação musical.

\section{CENA 1: UTILIZANDO A MÚSICA NA ROTINA}

Uma das cenas da escola em que as relações com música estão presentes são as rotinas. Ao revisar a literatura, percebi que essa utilização é algo bastante presente no contexto da educação infantil e, também, bastante criticado por autores(as) da área de educação musical.

Alguns dos momentos da rotina em que a música está presente são os que antecedem as refeições, como falou a professora Mary: "A gente canta para esperar o almoço, por exemplo. É uma das formas com que eles ficam tranquilos." Outro momento recorrente é a hora do sono, como contou a monitora Bruna: "[...] na hora do sono, que também é uma parte que acalma bastante". Em ambas as situações, a música é utilizada para que as crianças fiquem tranquilas. Durante a roda de conversa, percebi que a música na hora do sono, para além de acalmar, ajuda a criar uma atmosfera diferenciada, juntamente com as luzes que são apagadas, as cortinas que são fechadas e os colchões que são dispostos lado a lado, para as crianças descansarem.

A utilização da música na rotina tem sido objeto de reflexão das profissionais. Um exemplo disso foi trazido pela professora Fábia, quando lembrou de uma formação em que esse tema foi discutido com o grupo de profissionais. Retomei sua fala durante a roda de conversa. A professora disse acreditar que "fica uma coisa meio condicionada, era isso que eu estava 
falando: do guardar, musiquinha para guardar; na hora de comer, musiquinha para comer. Também não que seja essa a finalidade, não é legal, né?” Isabel discorda, quando diz: "Eu não vejo como condicionamento, sabe? Eu vejo, assim, como uma marcação da rotina. Eu acho que a gente tem vários simbolismos ali, e a música entra como algo simbólico, naquele momento, para marcar aquele momento."

O diálogo sinaliza que a intenção das professoras ao utilizarem músicas para a rotina não é a de controlar as crianças, mas auxiliá-las em ações necessárias para alguns momentos. Mesmo que a intenção não seja a de controlar, a professora Fábia percebe que há um "condicionamento" e acredita que isso não seja positivo.

A música na rotina é um elemento potencializador da organização dos tempos cronológicos e dos espaços na educação infantil. Dessa forma, oportuniza o exercício da capacidade de compreender que os diferentes espaços escolares - refeitório, saguão, salas das turmas e pátio - são coletivos.

Associo a prática de cantar ao realizar atividades cotidianas na educação infantil aos cantos de trabalho, que, conforme Santana (2017, p. 198), “[...] são manifestações que marcam atos cotidianos da vida comunitária e acompanham as atividades produtivas manuais, rurais ou urbanas, coletivas ou individuais de diversos povos em todo o mundo e das mais variadas profissões". Faço essa associação por identificar que as músicas na rotina também marcam atos cotidianos da vida comunitária, vivida pelas crianças e profissionais na escola de educação infantil.

\section{CENA 2: OUVINDO MÚSICAS}

Ouvir música é outra ação frequente na escola que não se restringe ao momento de sono descrito na primeira cena. A professora de educação física Mariana contou que a música "é um recurso pedagógico pra [ela]", que a auxilia a desenvolver suas propostas por ser algo a que as crianças respondem com prontidão.

Ouvir música, em muitas das falas, apareceu relacionado à ampliação de repertório, como falou Ana: "Sempre trouxe outros tipos de música também pras crianças, não só música infantil. Eu gostava de trazer música clássica... às vezes, botava uns pagodes que eles gostavam, umas coisas assim." Assim, Ana busca oportunizar o acesso a gêneros musicais variados, o que, conforme Maffioletti (2011, p. 69), "[...] pode ser uma forma de eliciar diferentes emoções e estados afetivos. Essa maleabilidade e fusão de sentimentos podem ser essenciais à convivência na diversidade que caracteriza o mundo contemporâneo."

Para Isabel, "teria que ampliar muito mais ainda, porque eles não têm... ainda é meio restrito esse repertório junto às famílias, na questão cultural, é pouco o que eles têm acesso. Então, que eles tenham acesso por meio da escola." Percebo que a intenção de ampliar o repertório é a de oportunizar que as crianças conheçam diferentes manifestações musicais, o que as põe em contato com outras formas de fazer música e lhes apresenta outras 
referências musicais. Além disso, ao apresentarmos diferentes músicas, possibilitamos que "os alunos [as crianças] reconheçam vários 'sotaques', para que, assim, possam reconhecer melhor, inclusive, o seu próprio 'sotaque' e, a partir daí, a seu critério, (re)significá-lo, ampliá-lo e/ou transformá-lo" (Queiroz, 2011, p. 20). Ampliar o repertório é ainda uma forma de buscar ampliar o mundo das crianças, um modo de introduzi-las no mundo.

\section{CENA 3: FAZENDO MÚSICA DURANTE O "BRINQUEDO LIVRE"}

As crianças também trazem seu repertório para o contexto escolar, o que aparece especialmente em alguns momentos e locais da escola, como contou Luciana: "Eu acho que no brinquedo livre a música aparece bastante. Eu noto, às vezes, eles brincando e cantando." Na mesma direção, Fábia diz que percebe que "eles se isolam pra cantar, eles fazem o showzinho deles [...]" e entende que,

quando as crianças vão brincar livre, que elas tão fazendo o que é importante pra elas, que é naquele momento que tu percebe o que a criança... do que que ela quer brincar, porque ela tá ali. Então, eu acho que, naquele momento, eu acho que é mais importante, porque é a criança que tá trazendo, não tu que tá [propondo].

A partir dessa fala, entendo que os momentos de brinquedo livre podem ser oportunidades para as profissionais identificarem propostas significativas para as crianças. A vice-diretora Isabel percebe que a música no brinquedo livre “[...] tem a ver com o jogo simbólico também, né?”. Esses cantos espontâneos das crianças também ocorrem nas salas das turmas, como contou Bruna: "Às vezes, quando eles tão sentados na mesa fazendo alguma coisa, daí surge a música e eles começam, mas mais no pátio." Para exemplificar, lembro que uma colega gravou, na sala de aula, uma menina tocando com o teclado do computador como se fosse um instrumento musical, brincando de dar aulas de música para seus colegas.

Percebo que o brinquedo livre, além de ser um momento em que as crianças trazem suas manifestações musicais e se expressam por meio da música, é uma situação propícia para trocas entre o espaço da escola e outros espaços frequentados pelas crianças, como suas casas. Para Maffioletti (2011, p. 68),

a vida social é continuada no convívio familiar do mesmo modo que as canções aprendidas em casa são compartilhadas na escola. Nas experiências de serem portadoras de cultura, as crianças constroem suas subjetividades incorporando a continuidade e a ruptura de serem ao mesmo tempo um ser individual e social. 


\section{CENA 4: FAZENDO MÚSICA COMO UMA ORQUESTRA}

Tomar a orquestra como uma referência musical é uma característica do trabalho da(s) professora(s) da oficina. Elas desenvolvem práticas musicais de uma forma diferente do modo como as professoras unidocentes e monitoras o fazem, tendo em vista alcançar o objetivo do trabalho desenvolvido pelo programa Orquestra Villa-Lobos.

Sobre essas oficinas, Ana relatou que a professora "ensinava tudo: o nome dos instrumentos, o que é alto, o que é baixo, agudo, grave". No mesmo sentido, Isabel diz: "As aulas vinculadas ao projeto social funcionavam como um ensaio em que havia um produto final, que era uma apresentação." $\mathrm{E}$ afirma que o objetivo "era mais uma coisa de... vamos aprender o ritmo, vamos aprender o compasso, vamos aprender... o que é extremamente válido e maravilhoso".

Nas falas em que as profissionais fazem referência às oficinas de música, aparecem termos como "ensino" e "aprendizagem" e é possivel identificar alguns conteúdos musicais trabalhados. Essas ideias remetem ao ensino de música no sentido de desenvolvimento musical e a um modelo profissional a orquestra. $O$ fazer musical está centrado na execução musical, o que pode ser identificado quando há a ideia de "ensaio". Mesmo assim, as colaboradoras valorizam o trabalho desenvolvido e acreditam que é significativo para as crianças, pois é uma prática de referência da comunidade da Vila Mapa.

\section{CENA 5: DANÇANDO E SE MOVIMENTANDO}

As relações com música aparecem frequentemente relacionadas às brincadeiras e à experimentação de gestos e movimentos corporais, como contou Mary: "A gente faz festa com música, dança, pula, [...]." Samanta, no mesmo sentido, conta que, ao escolher o repertório para utilizar com as crianças, toma como parâmetro músicas que "[...] sejam divertidas, porque a criança, ela é muito... ela não consegue ficar muito parada. Então, eu procuro trazer coisas que tenham alguma coisa com o corpo também." Assim, a monitora, ao promover propostas em que as crianças possam explorar a movimentação corporal - por perceber a necessidade delas -, busca oportunizar um momento de as crianças se expressarem e responderem corporalmente à música.

Maffioletti (2011, p. 86) reflete sobre possiveis aprendizagens oportunizadas às crianças pelas brincadeiras com música: "Participando de brincadeiras coletivas, elas aprendem no movimento dinâmico das cantigas de roda a incorporar a previsibilidade, a coerência e a regularidade que elas precisam para interpretar o ambiente onde vivem."

A dança, os gestos e os movimentos possibilitam que as crianças se conheçam, se expressem, desenvolvam suas capacidades corporais e interajam com seus pares e com as profissionais. O corpo, além de possibilitar o movimento, também é explorado através de suas sonoridades. 


\section{CENA 6: EXPLORANDO SONORIDADES}

Outra experiência oportunizada pelas diferentes profissionais é a exploração dos instrumentos musicais convencionais, do corpo e de outros objetos. Sobre a exploração dos instrumentos musicais convencionais, trago um exemplo relatado por Fábia, sobre a turma do Berçário II. A professora contou que costuma levar "os instrumentos também, mas [o uso d]os instrumentos é mais eles [explorarem], é mais livre. [...] eu tenho levado bastante, eles curtem muito". Ao levar os instrumentos musicais para as crianças, a professora oportuniza a exploração dos materiais, de modo que as crianças possam manipulá-los e experimentar suas possibilidades sonoras e expressivas.

A coordenadora pedagógica lembra que, além da utilização de instrumentos musicais convencionais, também utilizava objetos para realizar atividades musicais, e descreve: "[...] brincava muito de batucada com os bebês. Aí eu ia batucando de um lado pra outro, aî eu dizia: 'Pediu pra parar, parou' [cantando]. Eu fazia assim e aí eles paravam, daí ia de novo: 'Vamos lá, pessoal!' E batia..." Nessa proposta, a professora desenvolve com as crianças bem pequenas a experimentação de sons e silêncio - elementos fundamentais para se fazer música - com objetos do cotidiano.

Durante a entrevista individual, a monitora Bruna trouxe um exemplo de atividade para demonstrar como eram desenvolvidos conteúdos musicais: "Eu me lembro do aviãozinho [...] tu girava o aviãozinho para aquela parte [do som] ir mais alto, mais baixo." Essa era uma proposta de exploração dos instrumentos em que as crianças ficavam em roda e cada uma recebia um instrumento musical de percussão; eu ficava no centro com um avião de madeira preso a uma corda. O movimento do avião indicava o modo como os instrumentos tocavam (rápido, lento, forte e fraco). Assim, havia a combinação de dois elementos musicais: intensidade e velocidade do tempo. Depois, as próprias crianças iam para o centro da roda e movimentavam o avião.

A partir de propostas como essa, as colaboradoras identificam que: "Tu [Joana] trazia propostas lúdicas, propostas desafiadoras, mas sempre com aquele objetivo de dar aquelas coisas da música mesmo, que eu, por exemplo, eu não saberia dar. Então, teus planejamentos, a tua intencionalidade [eram diferentes dos nossos]."

Independentemente das profissionais que realizam as propostas, entendo que, através das explorações das sonoridades dos instrumentos, do corpo e de outros objetos, as crianças entram em contato com as fontes sonoras e com a materialidade da música. Ao explorarem e manipularem essas fontes sonoras, as crianças se expressam, brincam, interagem, descobrem as possibilidades de seus corpos e dos materiais disponiveis na escola, conhecendo mais recursos para se expressarem. Além disso, elas são apresentadas aos instrumentos musicais por seu nome e pelos sons que são capazes de produzir. 


\section{CENA 7: COMPONDO MÚSICAS}

Diversas colaboradoras lembraram de uma prática de composição desenvolvida especialmente pela monitora Luciana. Nas palavras de Bruna, "ela sempre está no Jardim e ela sempre tenta criar músicas com as turmas dela e é muito legal. Acho que a Lu é mais uma referência musical na escola."

Perguntei à monitora como era esse processo de composição que realizava com as crianças, a fim de compreender melhor o modo como desenvolvia a proposta e o modo como as crianças participavam e se engajavam nela. Luciana contou: "Eu vejo algumas brincadeiras, algumas coisas que eles tão fazendo com música, daí eu digo: 'Oh! Essa música é tão legal, e se a gente fizesse uma pra nós?'."

A partir do repertório que as crianças conhecem, a monitora sugere uma apropriação da música por meio da escrita coletiva da letra da canção, em que as crianças podem "falar" sobre o que quiserem. A partir das explicações da monitora, percebo que a intenção de Luciana ao compor com as crianças é que elas se expressem verbalmente, partindo de algo do seu interesse e de uma música já existente, ou seja, elaboram paródias.

A professora Ana falou sobre uma prática de improvisação que ocorria nas aulas de música, ela disse: "Eu achava fantástica a tua tranquilidade deles poderem usar o teclado, se sentirem autores na tua aula, saberem esperar a vez e virem protagonizar o seu momento. Bah! Tudo isso foi muito significativo pras crianças, muito mesmo." Esse momento também foi lembrado por Isabel, quando relatou: "E a expectativa das crianças na tua chegada, deles mexerem, tu deixar mexer no teclado, tocarem a música deles, deles se sentirem protagonistas daquele momento."

Esses momentos lembrados por Ana e Isabel, em que as crianças usavam o teclado e "protagonizavam seu momento", eram pensados por mim como uma proposta de improvisação. Nessas improvisações, nosso "diálogo" era por meio da música, as variações nos elementos eram feitas sem aviso verbal e a criança poderia "responder" do modo como quisesse, indo ao encontro da mudança que eu havia proposto ou mantendo sua forma anterior de tocar. $\mathrm{Na}$ maioria das situações as crianças respondiam vindo ao encontro do que eu estava tocando. Havia ainda momentos em que eram as crianças que variavam algum elemento - como o andamento; então, era eu quem ia ao encontro delas.

\section{CENA 8: FAZENDO MÚSICA NA RODA}

O canto também é uma atividade frequente na escola que, geralmente, acontece em rodas, como contou Isabel: "[As] monitoras e [as] professoras [...] fazem rodinha com as crianças e cantam." As falas das professoras sobre as chamadas rodas indicam que esse é um momento significativo de interação entre as profissionais e as crianças.

As interações que ocorrem na roda são fortemente mediadas pela música, o que é evidenciado na fala de Mary: "Eu acho que a música é tudo na rodinha." Ela acredita que, no momento da roda, "a música é quem manda até 
que eles comecem a falar. Cantar e fazer os gestos também." Nesse trecho, a linguagem musical e a linguagem dos gestos aparecem como linguagens que antecedem a fala.

A professora Fábia relata: "Tu começou a cantar, quando vê, forma a roda. Tu começou a cantar com um ou dois, quando vê, tá uma roda formada." Isso sinaliza o vínculo das crianças com essa linguagem. Elas fazem música porque precisam disso, porque é significativo para elas, pois é uma das formas pelas quais se inserem no mundo. Além disso, há uma ideia de coletividade, pois querem fazer música com os outros.

A música, nesses momentos, possibilita outra forma de interação entre crianças e adultos, em que cada um(a) compartilha seu repertório musical e são executadas músicas significativas para o grupo. Assim, entendo que as rodas na Emei Maria Marques Fernandes estabelecem um espaço de encontro entre as profissionais e as crianças. Nesses momentos, os sujeitos interagem e se expressam, entrando em contato com outros que são diferentes deles.

\section{CONCLUSÃO}

A partir da disposição para o outro, as profissionais buscam desenvolver ações e práticas tendo como finalidade o desenvolvimento integral das crianças, oportunizando experiências lúdicas, para que elas possam se apropriar do mundo e construir significados. Essa apropriação do mundo - e, também, da escola como um mundo - é feita através das relações que as crianças estabelecem com esse mundo. A partir dos dados analisados, percebi que essas relações com música são muito presentes na instituição e que elas são um modo de as crianças se apropriarem do mundo, já que o som é "[...] um modo totalmente único de interpretar e construir o mundo" (Bowman, 1994a, p. 53).

Essas relações com música são mediadas pelas diferentes profissionais que trabalham na escola e oportunizam que as crianças se aproximem da linguagem musical, brinquem e interajam umas com as outras e com as profissionais, mobilizem suas emoções, expressem seus sentimentos, aprendam a se organizar individual e coletivamente, aprendam a estar com os outros, desenvolvam habilidades como raciocínio, autonomia, imaginação, criatividade e fala.

Concluo que as diferentes formas de mediar as relações com música contribuem para o projeto formativo de crianças de uma escola de educação infantil quando atendem ao propósito desse projeto formativo: o desenvolvimento integral das crianças. Desse modo, o projeto formativo não busca o domínio de diferentes campos de conhecimento, mas os mobiliza de forma que possam contribuir para o desenvolvimento integral das crianças.

A música - como um desses campos de conhecimento - funciona, assim, como dispositivo de formação das crianças. As relações das crianças com música as auxiliam a adquirirem as habilidades, disposições e sensibilidades para as quais se propõe o projeto formativo, sendo uma das maneiras pelas quais as diferentes profissionais as colocam em contato com o mundo, o que possibilita que se aproximem de formas de usar a linguagem musical e que se formem através das relações que estabelecem com a música. 


\section{REFERENCIAS}

BIESTA, Gert. Para além da aprendizagem: educação democrática para um futuro humano. Belo Horizonte: Autêntica, 2017.

. O dever de resistir: sobre escolas, professores e sociedade. Revista Educação, Porto Alegre, v. 41, n. 1, p. 21-29, jan./abr. 2018.

BOWMAN, Wayne. Sound, sociality, and music: part one. The Quarterly Journal of Music Teaching and Learning, Greeley, v. 5, n. 3, p. 50-59, 1994a.

. Sound, sociality, and music: part two. The Quarterly Journal of Music Teaching and Learning, Greeley, v. 5, n. 3, p. 60-67, 1994b.

.The ethical significance of music-making. Music Mark Magazine, London, n. 3, p. 3-6, 2014.

CHARMAZ, Kathy. A construção da teoria fundamentada: guia prático para análise qualitativa. Porto Alegre: Artmed, 2009.

DEL-BEN, Luciana; PEREIRA, Joana Lopes; MACEDO, Vanilda Lídia Ferreira de; GAULKE, Tamar Genz; PIMENTEL, Maria Odília de Quadros; COTRIM, Cássia Vanessa Oliveira; FRACASSO, Daniela Cesa; PUERARI, Marcia; DAENECKE, Elaine Martha; PEDRINI, Juliana Rigon. Sobre a docência de música na educação básica: uma análise de editais de concurso público para professores. Opus, [s. l.], v. 22, n. 2, p. 543-567, dez. 2016.

DUARTE, Rosângela; KEBACH, Patrícia. O ensino da música na educação infantil: ouvindo o que os professores pedagogos pensam e sentem a respeito. In: CONGRESSO ANUAL DA ABEM, 19., 2010, Goiânia. Anais [...]. Goiânia: Abem, 2010. p. 1435-1443.

EMEI MARIA MARQUES FERNANDES. Projeto politico pedagógico. Porto Alegre: Emei Maria Marques Fernandes, 2018.

FIGUEIREDO, Sérgio Luiz Ferreira de. A pesquisa sobre a prática musical de professores generalistas no Brasil: situação atual e perspectivas para o futuro. Em Pauta, Porto Alegre, v. 18, n. 31, p. 30-50, 2007.

KOHAN, Walter Omar. A infância da educação: o conceito de devir-criança. In: KOHAN, Walter Omar (org.). Lugares da infância: filosofia. Rio de Janeiro: DP\&A, 2004. p. 51-68.

Palavras, passos e nomes para um projeto. In: KOHAN, Walter; OLARIETA, Beatriz Fabiana (org.). A escola pública aposta no pensamento. Belo Horizonte: Autêntica, 2012. p. 13-49. 
MAFFIOLETTI, Leda. A música na infância e as experiências de compreensão do outro. In: SALGADO, Rachel; ROCHA, Simone A. da (org.). Educação infantil: as crianças e a linguagem na/da infância. Cuiabá: EdUFMT, 2011. p. 83-96.

MARTINEZ, Andreia Pereira de Araújo; PEDERIVA, Patrícia Lima Martins. Concepções e implicações para o ensino da música na educação infantil. Música Hodie, Goiânia, v. 12, n. 2, p. 210-219, 2012.

PEREIRA, Joana Lopes. Construindo trajetórias de trabalho na educação infantil: perspectivas de professores(as) de música da Rede Municipal de Ensino de Porto Alegre. 2015. Dissertação (Mestrado em Música) - Instituto de Artes, Universidade Federal do Rio Grande do Sul, Porto Alegre, 2015.

QUEIROZ, Luis Ricardo da Silva. Diversidade musical e ensino de música. Salto para o Futuro: Educação Musical Escolar, Brasília, DF, ano 21, n. 8, p. 17-23, jun. 2011.

RÖPKE, Camila Betina. Professores de música na educação infantil: características de formação e atuação. In: CONFERÊNCIA REGIONAL LATINO-AMERICANA DE EDUCAÇÃO MUSICAL DA ISME, 11., 2017, Natal. Anais [...]. Natal: ISME, 2017. Sem paginação.

SANTANA, Sandro Luiz Cardoso. Memória e esquecimento nos cantos de trabalho da Quixabeira. Extraprensa, São Paulo, v. 10, n. 2, p. 193-209, 2017.

SCARAMBONE, Denise Cristina Fernandes. Práticas musicais na educação infantil: uma pesquisa-ação. In: CONGRESSO DA ASSOCIAÇÃO NACIONAL DE PESQUISA EM PÓS-GRADUAÇÃO EM MÚSICA, 24., 2014, São Paulo. Anais [...]. São Paulo: Anppom, 2014. Sem paginação.

SPANAVELLO, Caroline Silveira; BELLOCHIO, Cláudia Ribeiro. Educação musical nos anos iniciais do ensino fundamental: analisando as práticas de professores unidocentes. Revista da Abem, Porto Alegre, v. 13, n. 12, p. 89-98, mar. 2005.

STAKE, Robert E. Investigación con estudio de casos. Madrid: Ediciones Morata, 1999. 
Joana Lopes Pereira é doutora e mestra em Música, área de concentração Educação Musical, pela Universidade Federal do Rio Grande do Sul (UFRGS) e licenciada em Música pela mesma universidade. Trabalhou como professora de música da Rede Municipal de Ensino de Porto Alegre entre 2012 e 2017 e, desde 2017, é professora de música do Colégio de Aplicação da UFRGS. https://orcid.org/0000-0003-2799-9021 